\title{
CONVERSION OF SALZGITTER BATCH TANDEM MILL INTO A SEMI-CONTINUOUS TANDEM MILL*
}

Stefan Thelen ${ }^{1}$ Roman Schneeweis ${ }^{2}$ Martin Pointner ${ }^{3}$

\begin{abstract}
In November 2013 Salzgitter restarted their tandem mill after two weeks of shutdown, during which the existing mill entry equipment has been removed and replaced by new entry area equipment including pay-off reels, welding machine and a vertical entry looper for continuous feeding of the 5-stand tandem mill. It turned out to be beneficial to both product quality and production capacity.

Keywords: Vertical entry looper; Semi-continuous tandem mill; Surface quality; Offgauge length.
\end{abstract}




\section{INTRODUCTION}

The idea to change their tandem mill from batch production to (semi-)continuous production was not new to the Salzgitter people. More than two thirds of all wellknown tandem mills in the world are continuous mills. Although production capacity and product quality of the Salzgitter tandem mill were veritably satisfying and the threading process was working without problems - at least most of the time - it was tempting to get rid of strip threading and gain advantages from a more continuous process.

From this improvements were aimed by reduction of the off-gauge length and an increase of the output (also with regard to the subsequent lines). Furthermore the production costs shall be reduced through e.g. increasing the life of work rolls and reducing the adjustment work on the produced material. One idea was to widen the product range through improvements on the surface quality of cold rolled material. One last aspect was the possibility to link the tandem mill to the new continuous pickling line, which had been installed in the year 2007.

Finally this was enough motivation to concretize the plan.

\subsection{Strategy}

One challenge was to develop a procedure which on the one hand allows a short down time and on the other hand ensures a quick and safe commissioning of the new line, since most of the Salzgitter products run through the tandem mill. Once the shutdown has started, meeting the time line was crucial.

Therefore it was decided to install a continuous entry line and leave the exit area as it was (without flying shear and second recoiler).

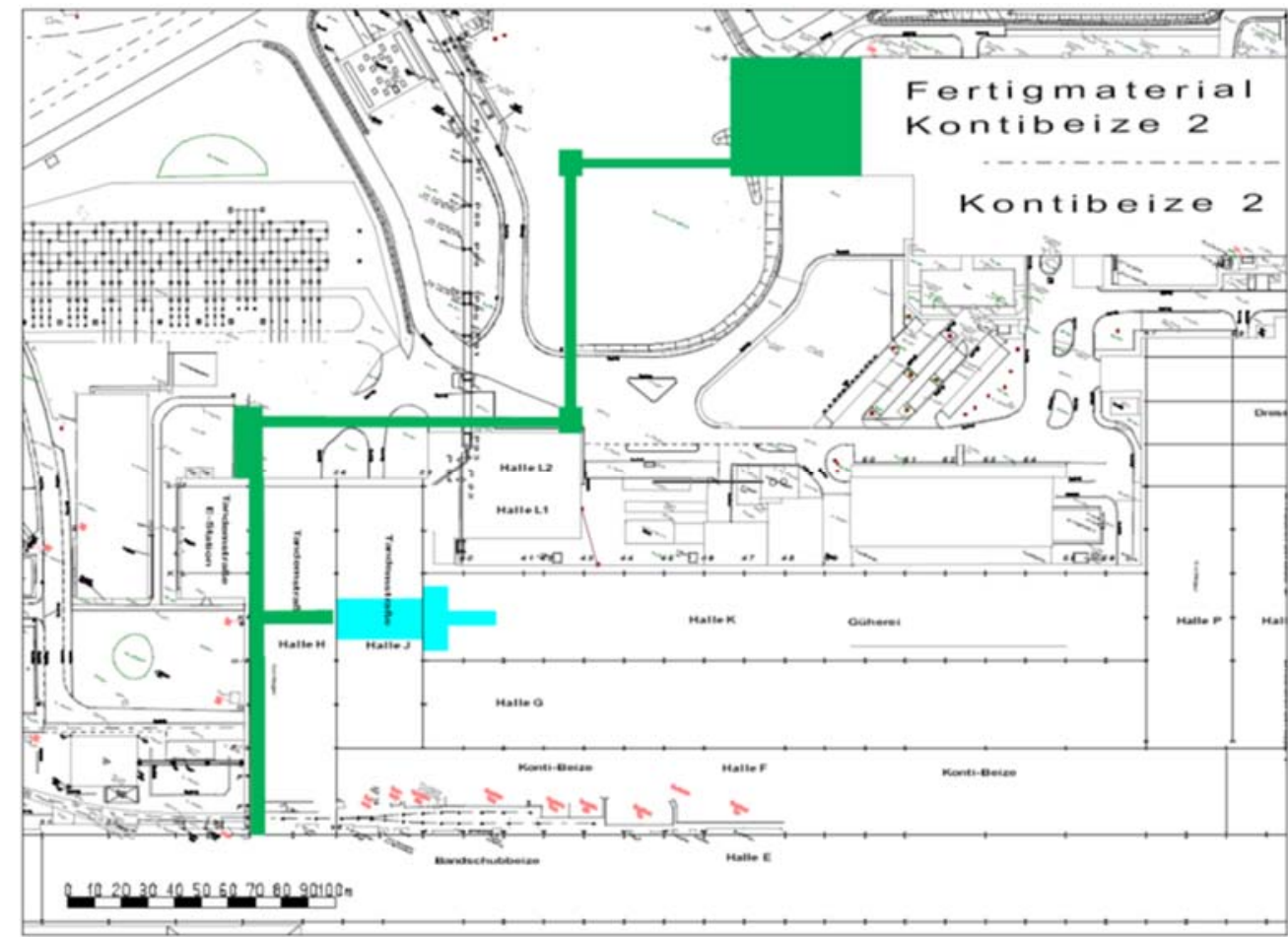

Figure 1. Possible link between pickling line (green square) and existing tandem mill (light blue). 
In the year 2006 a study for a continuous tandem mill was authorized. Two years later the project was approved by the board. In December 2008 the project was stopped due to the well-known financial crisis.

\subsection{Layout}

Until there various layouts had been discussed. It turned out, that the link between pickling line and tandem mill was not straight forward but included at least three direction changes (Figure 1).

It seemed in most bidders minds the linkage between pickling line and tandem mill had highest priority compared to the other aims listed above, which were of more interest for Salzgitter.

One bidder had a completely new concept - without linking pickling line and tandem mill (Figure 2).

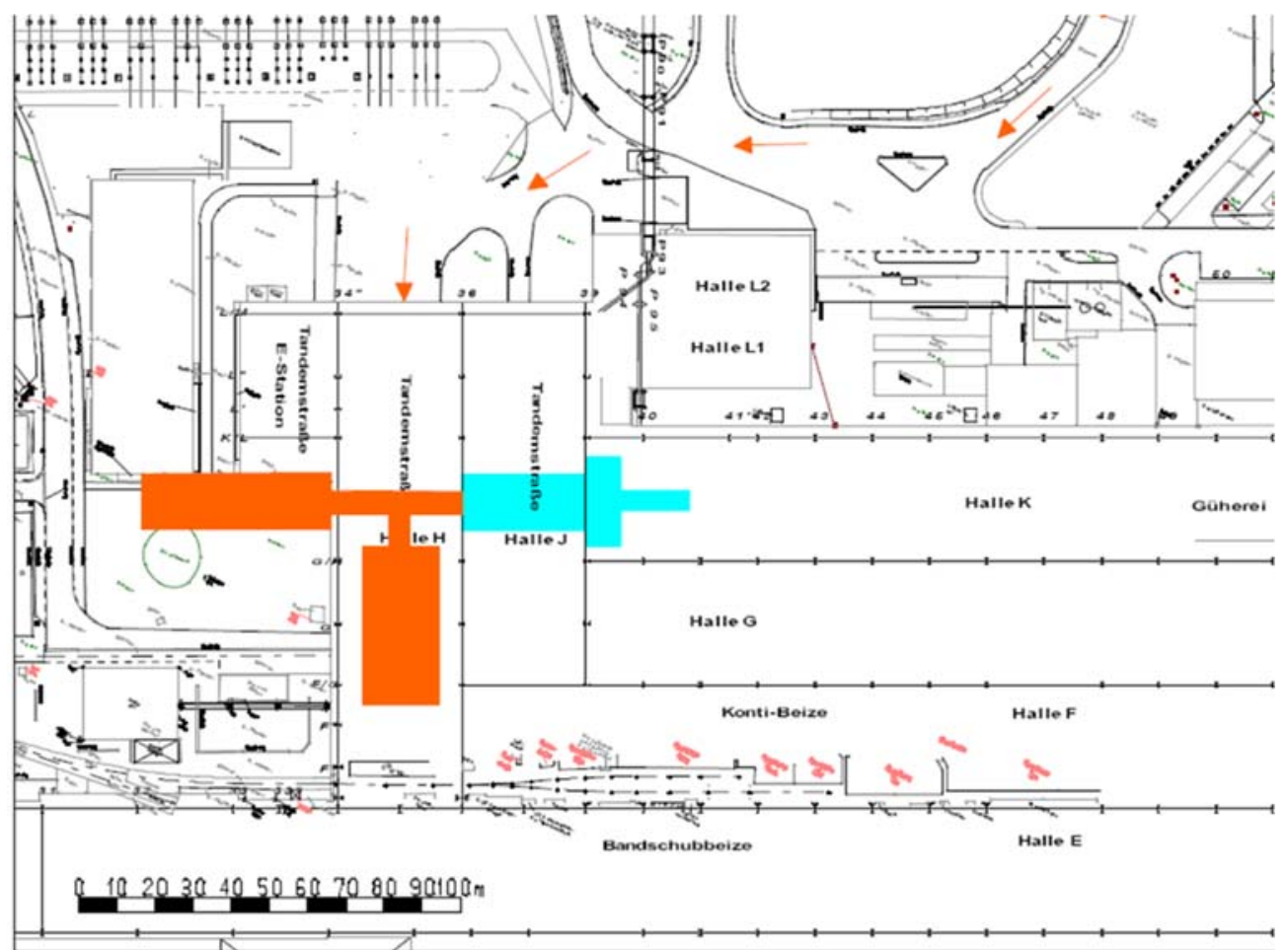

Figure 2. Alternative layout with priority to improvement on process and products.

\subsection{Re-entry into the project}

Again two years later in December 2010 - when the business environment offered better prospects - the project was renewed and half a year later in June 2011 the contracts for the new entry equipment, the welding machine and the technological adaption of the tandem mill were signed.

Messrs. BWG / H. Kleinknecht were awarded with the contract for the new entry equipment, Messrs. Miebach for the welding machine and pa-innovations for the technological adaption incl. level 2. Civils were made by Salzgitter under the use of local suppliers. This included groundwork, a new electrical building, a building for scrap disposal, the housing for the new looper towers and some refurbishment of the existing so called "Halle H", where space for former coil storage was prepared to meet the requirements for the new entry equipment. 
The new installation comprises walking beams, automatic binding strap removal, coil preparation station, coil car to serve both auxiliary unwinder and pay-off reel, straightener, several cross cutting shears, laser welding machine, deviating roller, vertical looper towers with structural steel work independent from the housing construction as well as several bridle rolls, pinch rolls and strip steering units.

With this concept only one change of strip run direction was necessary, for which a deviating roller has been installed between welding machine and entry looper. The vertical entry looper, which is designed for $1900 \mathrm{~mm}$ wide and $6,4 \mathrm{~mm}$ thick hot rolled material, consists of two looper towers, where each of them can take 300 meters strip length. The figures below show new buildings (Figure 3) and the entry area equipment incl. welding machine (Figure 4).

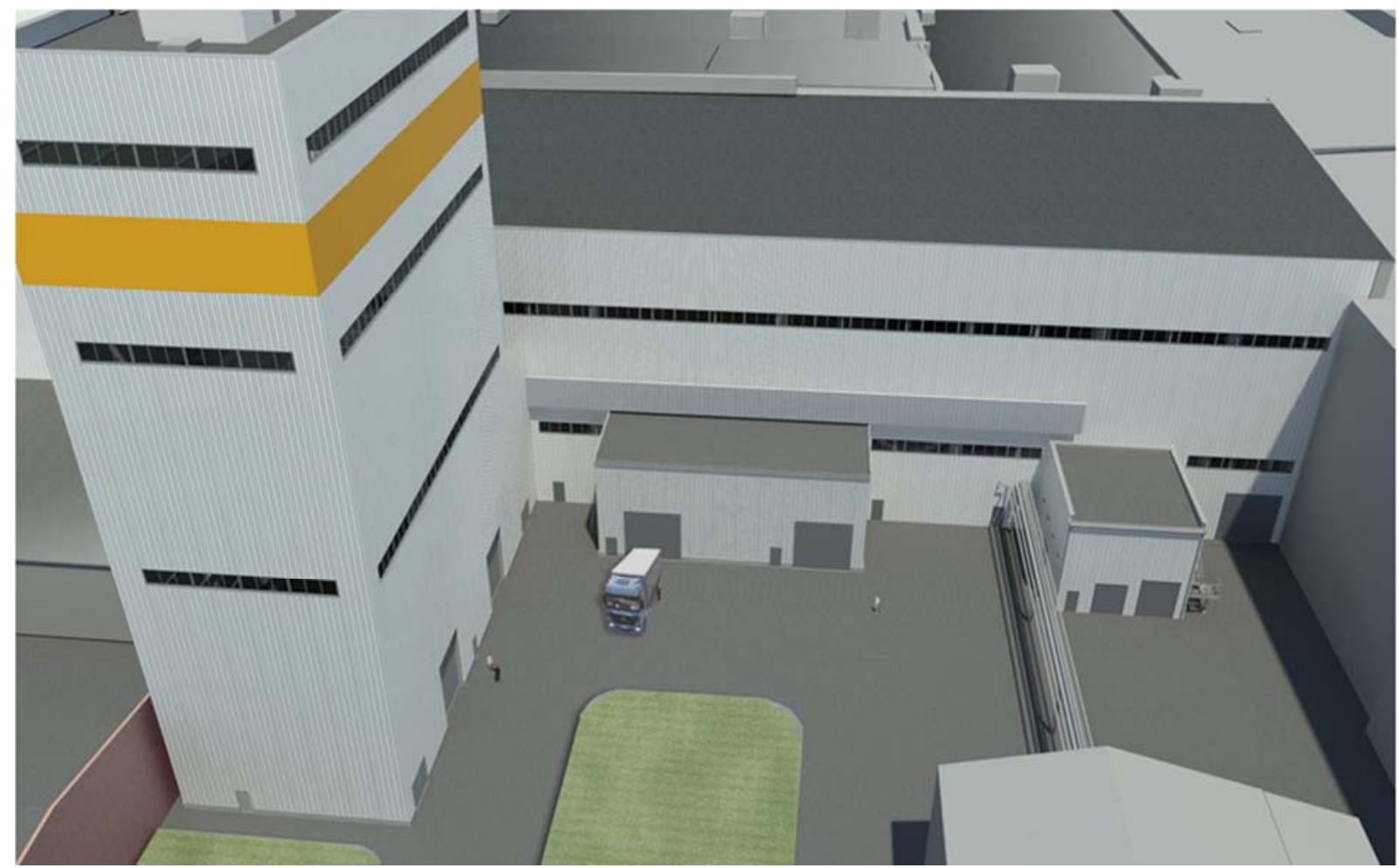

Figure 3. Housing for new looper towers, annexes for scrap disposal and electrical equipment.

\subsection{Automation System}

Existing automation layout (PCS7, VAntage TCS, Level 2 VME-system) was extended to the new entry area equipment and enhanced with regard to the existing technological control system.

The existing PLC for entry area was made redundant - it provided control for former entry walking beam, entry coil car, coil preparation station, pay-off reel as well as some equipment in front of mill stand \#1 - and replaced by two new PLCs; one for entry coil transport including coil data handling and the second PLC for complete strip run, looper control and material tracking up to the mill stands. 


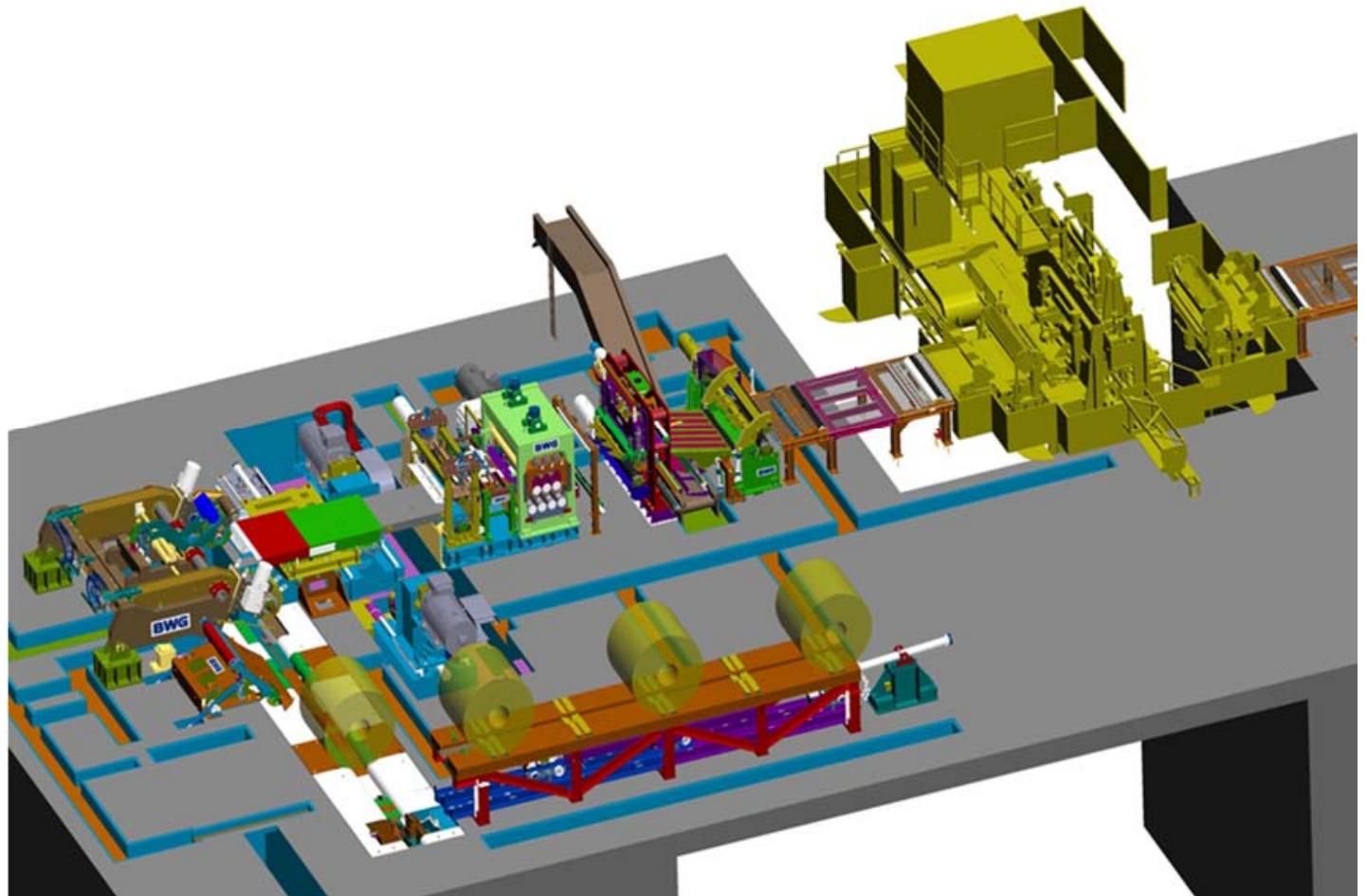

Figure 4. Entry coil transport, unwinders, straightener, cross cut shear with scrap shear and welder (entry pulpit removed for better view).

The new entry area is grouped into about 40 safety areas with various door interlocks, enabling switches, maintenance mode switches etc. For these controls a new Siemens safety-PLC was included in the supply. The interface to the existing PILZ safety-PLC is hard wired to PILZ remote $\mathrm{I} / \mathrm{O}$ units mounted in the new safety PLC cubicle.

A new HMI system was supplied only for the laser welder. Apart from that the existing WinCC HMI system was extended to the new entry area equipment, too. Initially there were some concerns in having three parties working on one single system (SZFG, BWG/Kleinknecht and pa-innovations). But - as it is known now - every party was aware of their responsibilities and the really good co-operation between all persons involved throughout the whole project became especially clearly here for instance.

\subsubsection{Tandem Mill Automation}

Major items at tandem mill Level 1 automation were the adaption of material tracking for a continuous process, the adaption of the FGC-function for weld passing, the design of an appropriate interface to the new entry speed reference generation system and on top dummy stand rolling and the implementation of a new tension control concept, which helped to reach better thickness performance and a considerably reduction of the off-gauge length at the strip head end.

In level 2 various reference tables for the entry equipment were implemented. Finally even the welding machine parameters are handled on the level 2 system. The already voluminous reporting system was considerably expanded for both the new entry and the existing tandem mill equipment (e.g. cycle time analysis, roller data base etc.).

A very important part of the enhanced level 2 system is the speed optimization algorithm for the entry looper. By estimation of time periods for rolling and entry as 
well as exit coil change speed references are given for looper entry and exit speed in order to maintain a continuous material flow to the tandem mill and to avoid unnecessarily high line speeds (Figure 5).

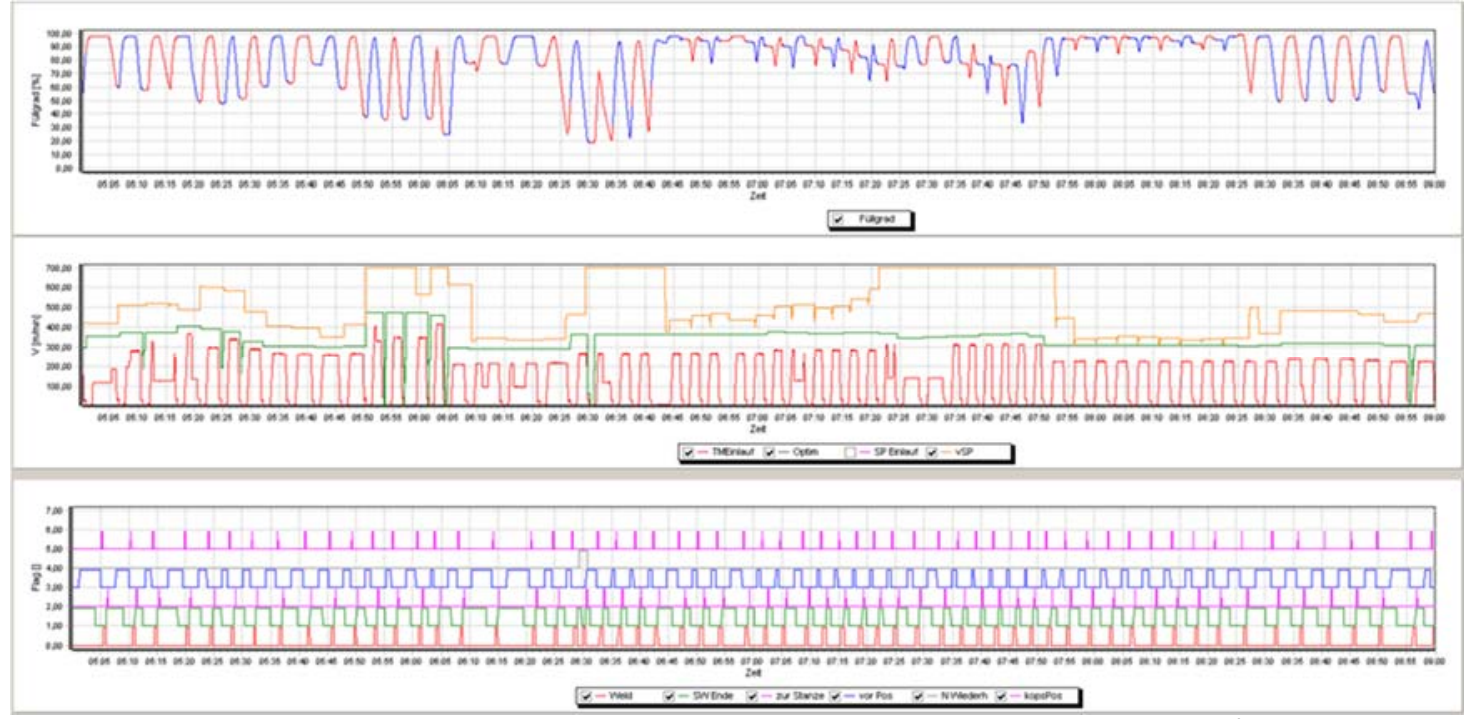

Figure 5. Chart entry looper content ( $1^{\text {st }}$ row $)$ and speed limitations ( $2^{\text {nd }}$ row).

\subsection{Timeline}

As mentioned above the project started in June 2011. About one year it was allowed time to finalize the functional specifications. Meanwhile the groundwork for the new entry looper had been done. Structural steel work for the entry looper (Figure 6) was ready in autumn 2012, entry looper housing in December 2012.

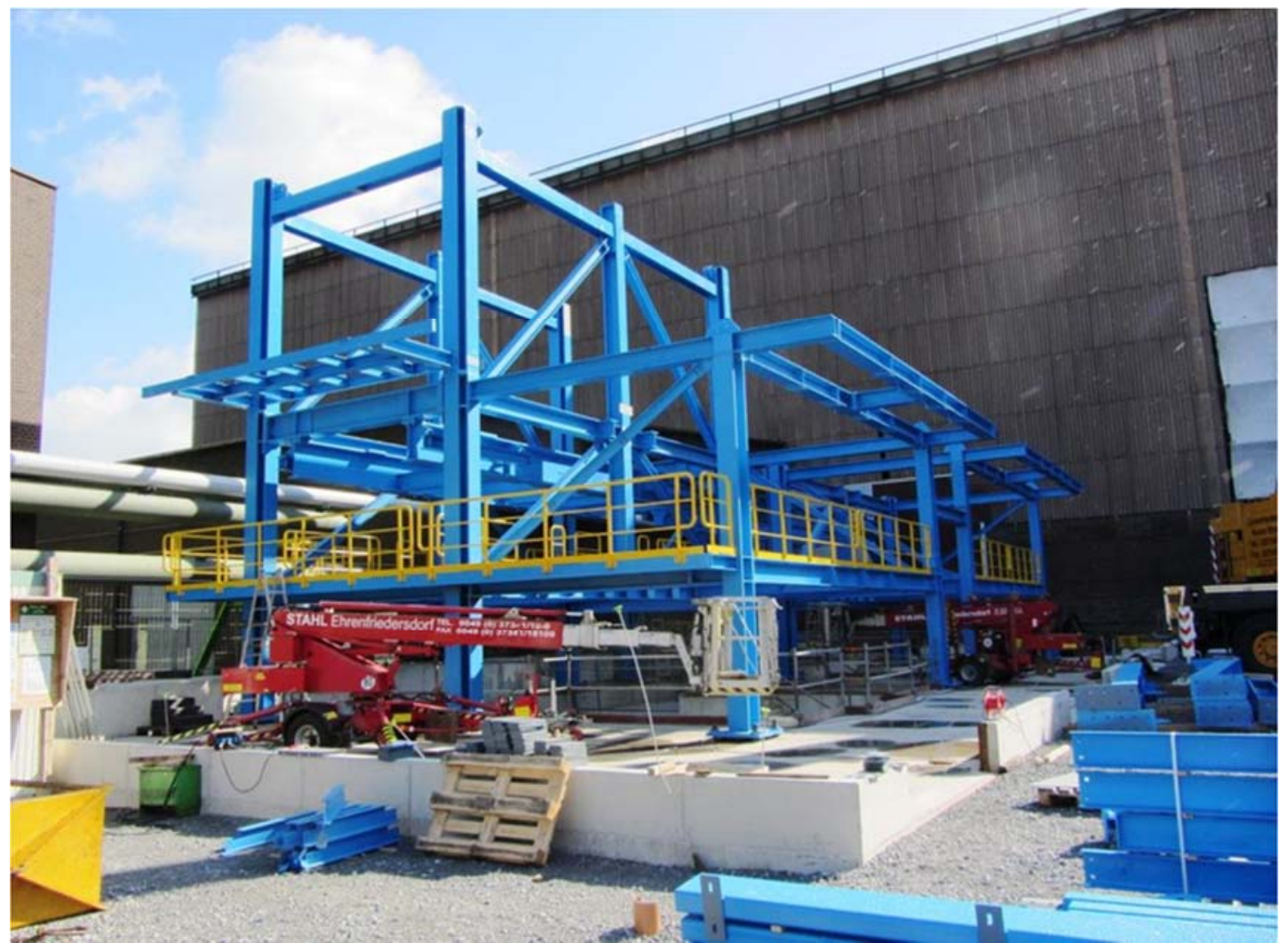

Figure 6. Start of structural steelwork looper towers. 
In May 2013 both mechanical and electrical erection had been completed for the so called "test operation with auxiliary recoiler" and function tests could start. I.e. the new equipment was installed as far as it was possible without touching the existing entry area equipment including a provisional recoiler with coil car.

Meanwhile software coding and integration testing with simulated mech. equipment took place and was finished in July 2013. Welding tests were both made in the Miebach workshop as well as on site after erection of the welder and have been completed in July 2013, too.

From this the test operation with provisional coiler commenced end of July 2013 and lasted for two months. This test operation was - and still is - considered a very important input to the successful startup of the henceforth semi-continuous tandem mill. The following four weeks "grace period" for unexpected, uncompensated time delay turned out unnecessary, which on one hand reflects the good co-operation between all parties involved an on the other hand was proved beneficial for the ongoing project. The further steps were on time, too: beginning of shut down on November 1st, first strip within EN10131 tolerances on November 14th, operational availability on November 26th, increased production capacity was reached end of January 2014.

The following figures show the arrangements in the new entry pulpit (Figure 7) and part of the new entry area equipment (Figure 8).

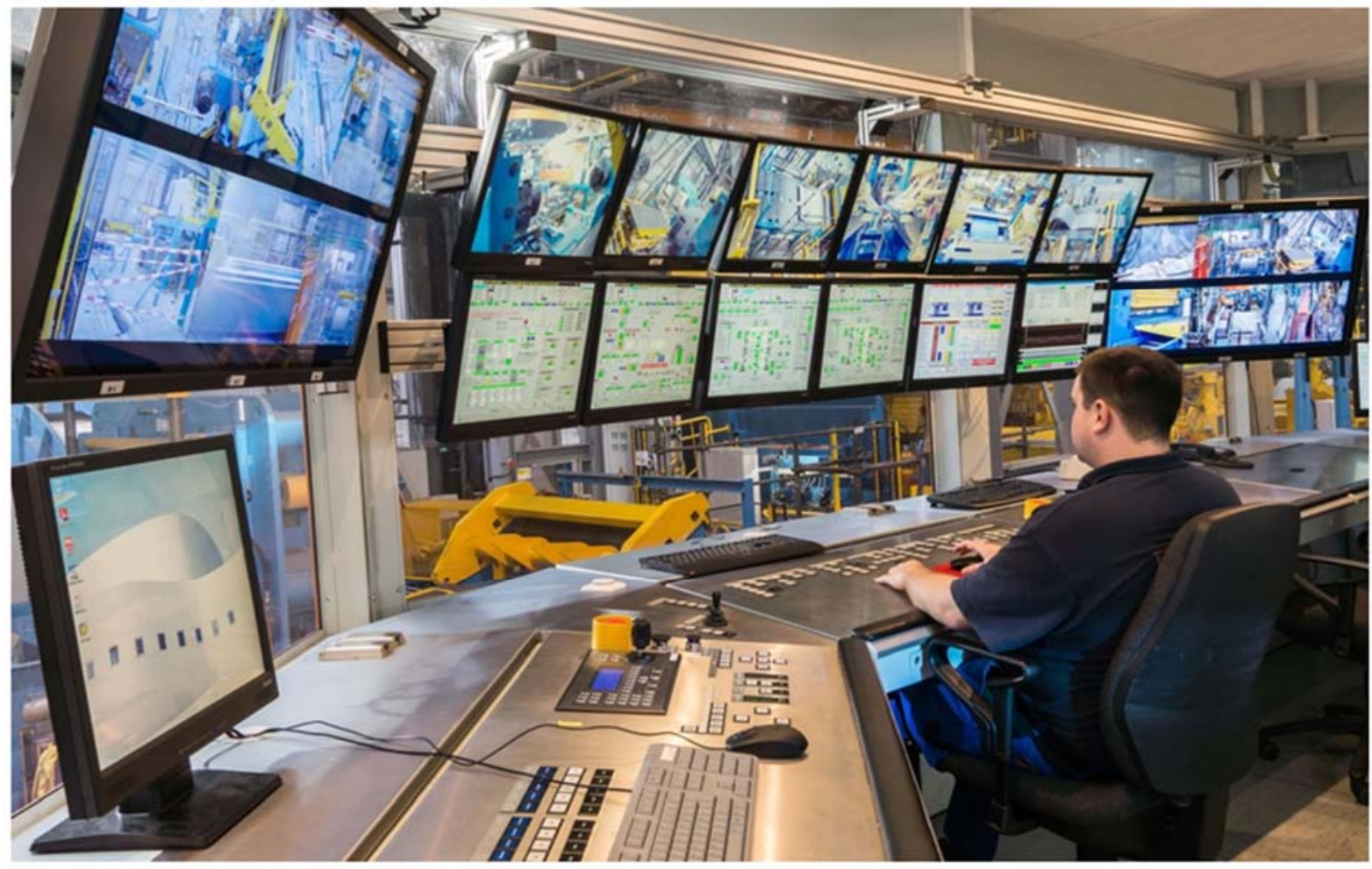

Figure 7. New entry pulpit. 


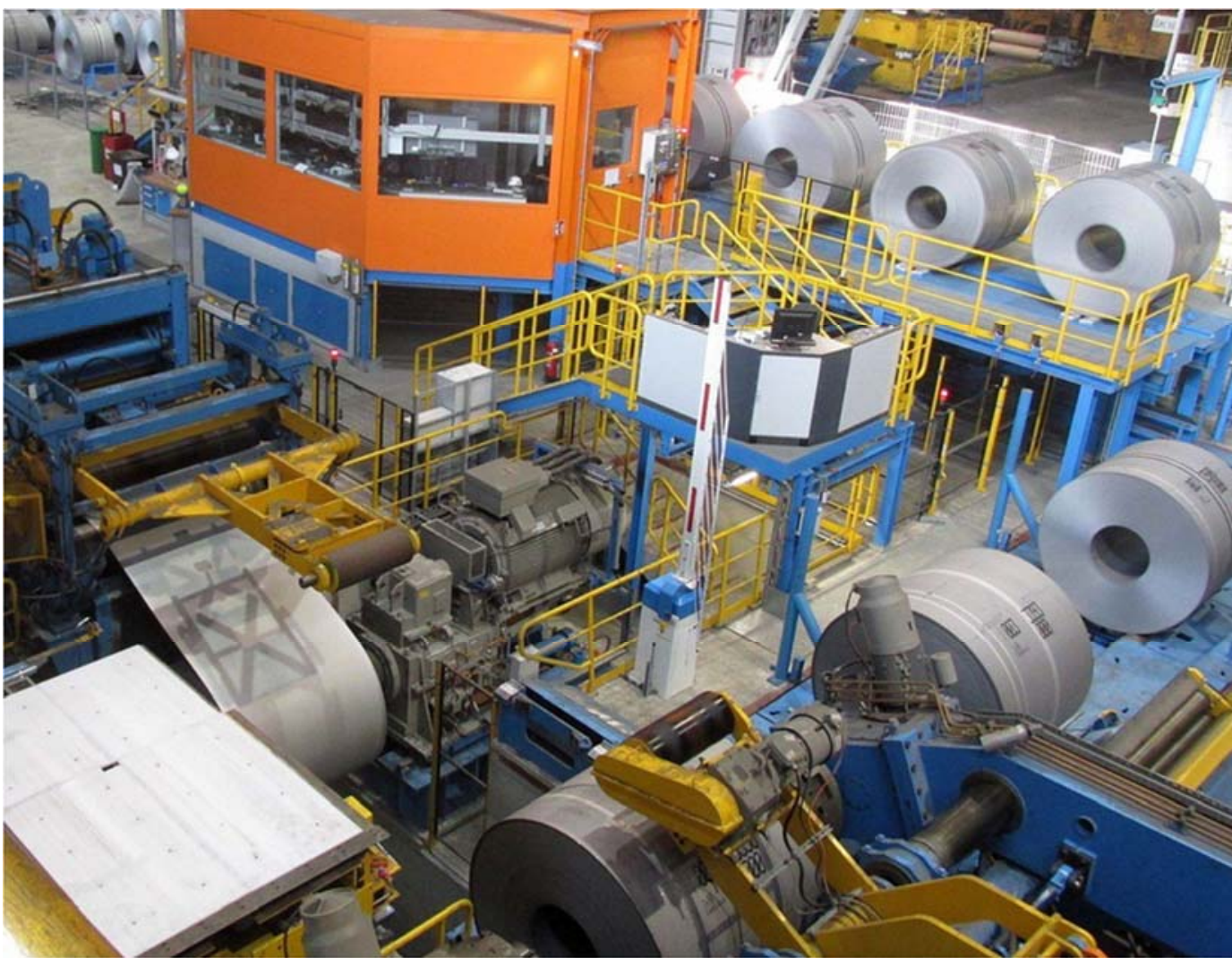

Figure 8. New entry area equipment with walking beams, coil car, auxiliary uncoiler and pay-off reel.

\section{MATERIAL AND METHODS}

Major technological improvement at the tandem mill was possible through implementation of an enhanced mass flow / tension controller (Figure 9).

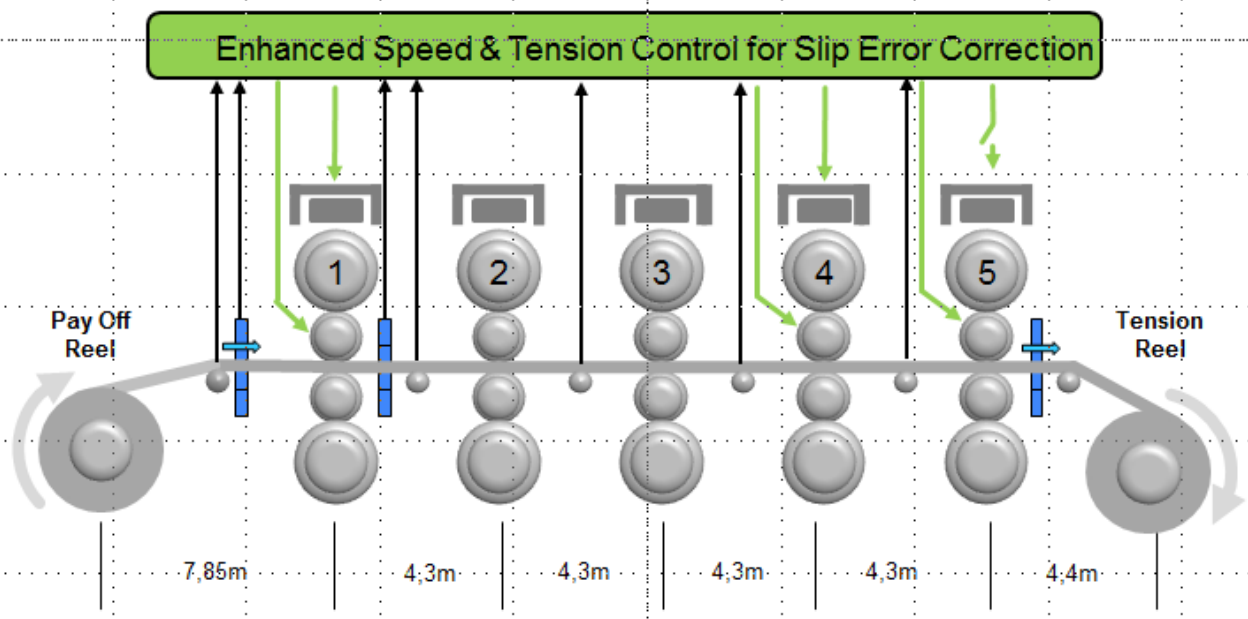

Figure 9. Enhanced mass flow-tension-control.

The target of the controller is to keep the mass flow through the complete mill constant even when the roll force is kept constant at the last stand (tandem mill sheet mode). Therefore the mass flow out of stand 1 is kept constant by controlling the measured forward slip of stand constant. Furthermore the forward and backward tension is controlled simultaneously with stand 4 thus the total speed correction of the last stand becomes zero. 


\section{RESULTS AND DISCUSSION}

The table below (Table 1) indicates the mill performance before and after the conversion.

Table 1. Project aims

\begin{tabular}{lccc}
\hline Item & before & aim & result \\
\hline Performance & 1,8 Mio t/a & 2,0 Mio t/a & ok \\
\hline $\begin{array}{l}\text { Work roll and IR-roll } \\
\text { change per 1000ton }\end{array}$ & 2,0 & 1,5 & ok \\
\hline Off-gauge length & $30 \mathrm{~m}$ & $12 \mathrm{~m}$ & $7,1 \mathrm{~m}$ \\
\hline Thick strip ends & HRThi-0,5mm & max. EN 10131 & ok \\
\hline Thickness tolerances & $+/-1 \%$ & $+/-1 \%$ for each mat.-class & ok \\
\hline Increase of HRThi & $100 \%$ & $110 \%$ & for $75 \%$ of coils \\
\hline Less degradation & $0,7 \%$ & $0,4 \%$ & $0,28 \%$ \\
\hline Output & $99,5 \%$ & $99,8 \%$ & ok \\
\hline Degr. automotive & $1,5 \%$ & $0,6 \%$ & $0,51 \%$ \\
\hline
\end{tabular}

HRthi --- hot rolled thickness.

Significant improvement was achieved at reducing the off gauge length at the strip head end primarily by implementation of the enhanced mass flow / tension controller, secondly at strip tail end through switch over to semi-continuous production mode and finally by a more stable mass flow control in the first mill stand because of better exit speed feedback as a consequence of the installation of a flatness measuring roll between mill stands one and two.

The improvements in off-gauge length throughout the project are shown in the figure below (Figure 10).

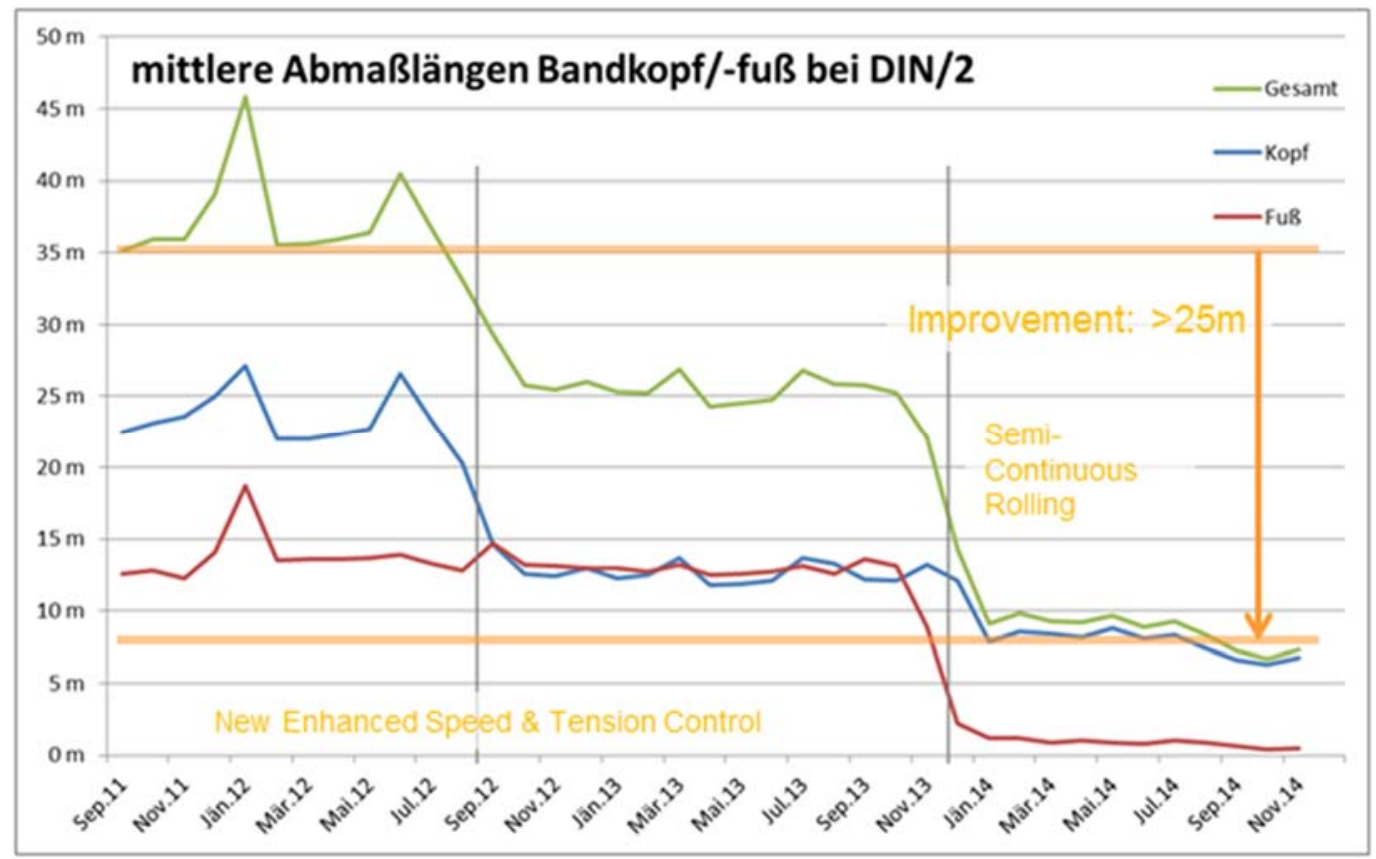

Figure 10. Improvement in off-gauge length by approximately 25 meters.

\section{CONCLUSION}

It can be summarized that all project aims have been reached. Thus the results justify the efforts undertaken and the investment. 